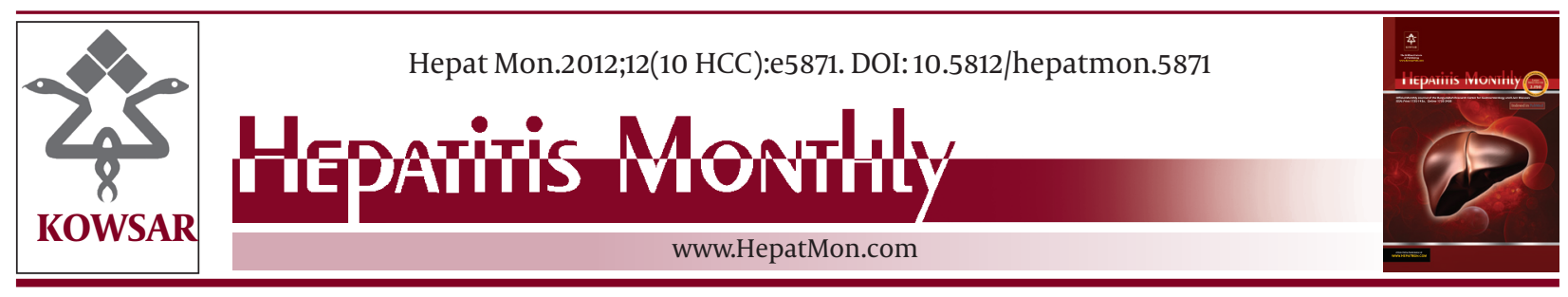

\title{
Coincidental Occurrence of Hepatocellular Carcinoma and Cholangiocarcinoma (Collision Tumors) After Liver Transplantation: A Case Report
}

\author{
Waleed Al Hamoudi ${ }^{*}$, Hatem Khalaf ${ }^{2}$, Naglaa Allam ${ }^{2}$, Mohammed Al Sebayel ${ }^{2}$ \\ ${ }^{1}$ Gastroenterology Unit, King Saud University, Riyadh, Saudi Arabia \\ ${ }^{2}$ Department of Liver Transplantation and Hepatobiliary-Pancreatic Surgery, King Faisal Specialist Hospital and Research Center, Riyadh, Saudi Arabia
}

\begin{tabular}{l}
\hline A R T I C L E I N F O \\
\hline Article type: \\
Case Report \\
\hline Article history: \\
Received: 20 Apr 2011 \\
Revised: 5 Sep 2011 \\
Accepted: 11 Oct 2011
\end{tabular}

\begin{abstract}
A B S T R A C T
Coincidental occurrence of hepatocellular carcinoma (HCC) and cholangiocarcinoma, known as "collision tumors", within a cirrhotic liver is rare. Herein, we report a case of liver transplantation (LT) in a patient with such collision tumors. Our patient was a 56-year-old woman with hepatitis $C$ virus-related cirrhosis and 2 focal hepatic lesions, measuring 1.5 and $3 \mathrm{~cm}$, in the liver segments 8 and 5, respectively. The lesion on segment 8 showed the typical radiological characteristics of HCC; however, the lesion in segment 5 showed an atypical vascular pattern and was closely associated with the inferior vena cava. Serum alpha-fetoprotein level was normal and serum carbohydrate antigen 19-9 (CA19-9) level was slightly elevated (63 U/mL); the extrahepatic spread of HCC was ruled out. The patient underwent an uneventful deceased-donor LT. Histopathological examination of the explant confirmed that the lesion on segment 8 was an HCC, but surprisingly, the lesion on segment 5 was found to be a cholangiocarcinoma. Six months after LT, the serum CA19-9 level was markedly elevated $(255 \mathrm{U} / \mathrm{mL})$, and the patient began experiencing abdominal pain. Magnetic resonance imaging showed enlarged hilar and paraaortic lymph nodes that were suggestive of metastases; histopathological analysis using ultrasound (US)-guided biopsy confirmed recurrent cholangiocarcinoma. Unfortunately, the patient died because of tumor recurrence 9 months after LT.

Collision tumor resulting from the co-existence HCC and cholangiocarcinoma in a cirrhotic liver is rare and has a negative impact on the outcome of LT. Atypical vascular pattern and elevated serum CA19-9 levels are suggestive of such tumors; patients with these findings should undergo a targeted biopsy to rule out the coincidental occurrence of HCC and cholangiocarcinoma.

Copyright $\odot 2012$ Kowsar Corp. All rights reserved.
\end{abstract}

- Implication for health policy/practice/research/medical education:

Combined hepatocellular and cholangiocarcinoma is a rare form of primary liver cancer that usually present as "mixed tumors" in which areas of hepatocellular and biliary epithelial differentiation are intimately mixed within the same tumor. However, and in extremely rare cases, combined hepatocellular and cholangiocarcinoma might present as "collision tumors" in which discrete foci of HCC and cholangiocarcinoma arise separately within the same liver with no direct contact between both tumors. Cholangiocarcinoma in cirrhotic livers is difficult to diagnose and can be easily mistaken for hepatocellular carcinoma; elevated serum CA19-9 and atypical vascular pattern on a dynamic imaging study should always elicit the suspicion of cholangiocarcinoma; targeted biopsy or fine needle aspiration should be always considered in such situations aiming to confidently role-out cholangiocarcinoma before considering liver transplantation.

\footnotetext{
* Corresponding author: Waleed Al-hamoudi, Gastroenterology and Hepatology Unit (59), Department of Medicine, King Saud University, P.O. Box 2925, Riyadh 11461, Saudi Arabia. Tel: +966-14671215, Fax: +966-14671217, Email:walhamoudi@gmail.com

DOI:10.5812/hepatmon.5871

Copyright@ 2012 Kowsar Corp. All right reserved.
} 
- Please cite this paper as:

Al Hamoudi W, Khalaf H, Allam N, Al Sebayel M. Coincidental Occurrence of Hepatocellular Carcinoma and Cholangiocarcinoma (Collision Tumors) After Liver Transplantation: A Case Report. Hepat Mon. 2012; 12(10 HCC): e5871. DOI: 10.5812/hepatmon.5871

\section{Background}

Focal hepatic lesions in cirrhotic livers are common and suggest the presence hepatocellular carcinoma (HCC). Appropriate diagnosis of these lesions is crucial in choosing appropriate treatment strategies, ranging from liver transplantation (LT) to regular follow-ups (1). Recent advances in imaging techniques, including contrastenhanced magnetic resonance imaging (MRI) can help accurately characterize most focal hepatic lesions; however, the risk of false diagnosis should always be considered, particularly in cases in which cholangiocarcinoma is suspected (2-4). Guided biopsy of the suspected lesions has very high sensitivity and almost absolute specificity; however, there is an underlying risk of malignant seeding after the procedure (5). Coincidental occurrence of HCC and cholangiocarcinoma, known as collision tumors, within a cirrhotic liver is rare. Herein, we report a case of LT in a patient with such collision tumors.

\section{Case Report}

We report the case of a 56-year-old woman presenting with decompensated cirrhosis caused by hepatitis $C$ virus (Genotype 4). As a part of our routine pre-transplant workup, we performed dynamic abdominal computed tomography (CT), which showed 2 focal hepatic lesions, measuring 1.5 and $3 \mathrm{~cm}$, in the liver segments 8 and 5, respectively. On dynamic imaging, the lesion in segment 8 showed the typical vascular pattern of an HCC (Figure 1A), but that in segment 5 showed an atypical vascular pattern and was closely related to the inferior vena cava (Figure $1 B$ ). Serum alpha-fetoprotein (AFP) level was normal, but serum carbohydrate antigen 19-9 (CA19-9) level was slightly elevated (63 U/mL); extrahepatic spread was ruled out. The patient was assumed to have HCC on the basis of the presence of 2 focal hepatic lesions within a cirrhotic liver having viral hepatitis, particularly the smaller lesion in segment 8 that showed the typical vascular pattern of HCC on dynamic imaging. The model for end-stage liver disease (MELD) score was below 14; however, because the patient met the Milan's criteria for selecting patients with an HCC for LT (6), she was listed for LT and underwent uneventful deceased-donor LT after a 3-month waiting period. Histopathological examination of the explant confirmed that the lesion on segment 8 was an HCC (Figure $2 A$ ), but that on segment 5 was a cholangiocarcinoma (Figure $2 B$ ). Further histological evaluation of the lesion on segment 5 revealed that the tumor cells expressed cytokeratin (CK) 7, CK19, and carcinoembryonic antigen (CEA) and lacked AFP expression, liver-specific antigens, CK20, and CD34. The cell morphology and phenotype of the tumor cells were consistent with those of cholangiocarcinoma. Our standard immunosuppression protocol includes tacrolimus, mycophenolate mofetil (CellCept), and a tapering course of steroids; however, on the basis of the findings of the 6-week follow-up examination of the

\begin{tabular}{|c|c|c|c|c|}
\hline & Before Transplant & $\begin{array}{l}\text { Three Months After } \\
\text { Transplant }\end{array}$ & $\begin{array}{l}\text { Six Months After Trans- } \\
\text { plant }\end{array}$ & $\begin{array}{l}\text { Nine Months After } \\
\text { Transplant }\end{array}$ \\
\hline ALT, U/L & 52 & 152 & 475 & 33 \\
\hline AST, U/L & 42 & 171 & 1590 & 49 \\
\hline $\mathbf{A L P}, \mathbf{U} / \mathbf{L}$ & 94 & 274 & 682 & 290 \\
\hline Bilirubin, $\mu \mathrm{mol} / \mathrm{L}$ & 11 & 10 & 315 & 93 \\
\hline $\begin{array}{l}\text { Findings of imaging } \\
\text { studies }\end{array}$ & 2 focal liver lesions & No liver lesions & Mass in the porta hepatis & $\begin{array}{l}\text { Mass in the porta } \\
\text { hepatis, abdominal } \\
\text { lymphadenopathy, and } \\
\text { bilateral lung metas- } \\
\text { tases }\end{array}$ \\
\hline $\begin{array}{l}\text { Clinical/histopathologi- } \\
\text { cal assessment }\end{array}$ & Mild ascites & $\begin{array}{l}\text { Biopsy was suggestive } \\
\text { of HCV recurrence }\end{array}$ & $\begin{array}{l}\text { Biopsy was suggestive of } \\
\text { acute cellular rejection }\end{array}$ & $\begin{array}{l}\text { Sepsis, bilateral lung } \\
\text { metastases, and respira- } \\
\text { tory failure }\end{array}$ \\
\hline $\begin{array}{l}\text { Alpha-fetoprotein level, } \\
\text { ng/mL }\end{array}$ & 12.7 & 8.9 & 4.6 & 4.4 \\
\hline Ca19-9, U/mL & 55 & 65 & 135 & 258 \\
\hline Immunosuppression & - & $\begin{array}{l}\text { Sirolimus, CellCept, } \\
\text { prednisone }\end{array}$ & $\begin{array}{l}\text { Pulse steroid, sirolimus, } \\
\text { CellCept }\end{array}$ & Sirolimus \\
\hline
\end{tabular}

Abbreviations: ALP; alkaline phosphatase, ALT; alanine aminotransferase, AST; aspartate aminotransferase. 
Figure 1. Dynamic Computed Tomography (CT) Before Liver Transplantation

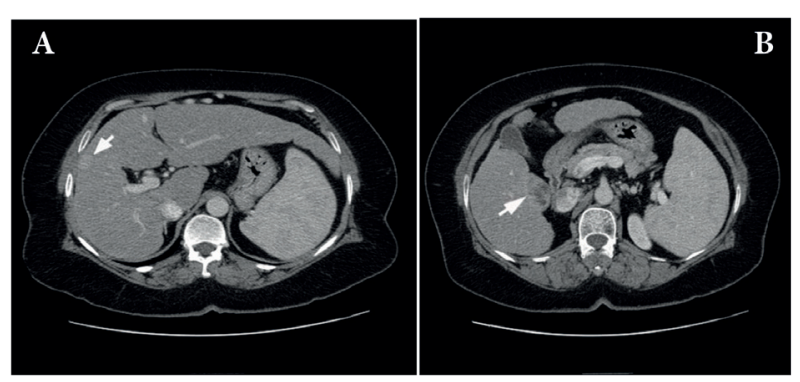

A) A 1.5-cm-size focal hepatic lesion with typical vascular pattern of hepatocellular carcinoma (HCC) in segment 8; B) A 3-cm-size focal hepatic lesion with atypical vascular pattern of HCC in segment

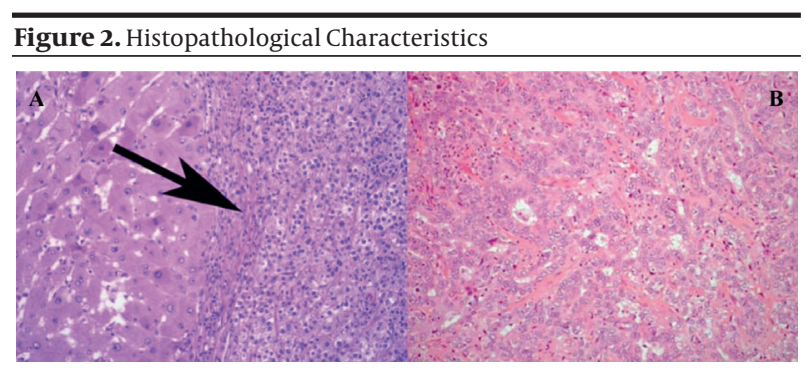

A) The lesion in segment 8 showing hepatocellular carcinoma; B) The lesion in segment 5 showing cholangiocarcinoma (hematoxylin and eosin [H\&E] staining; magnification $\times 20$ )

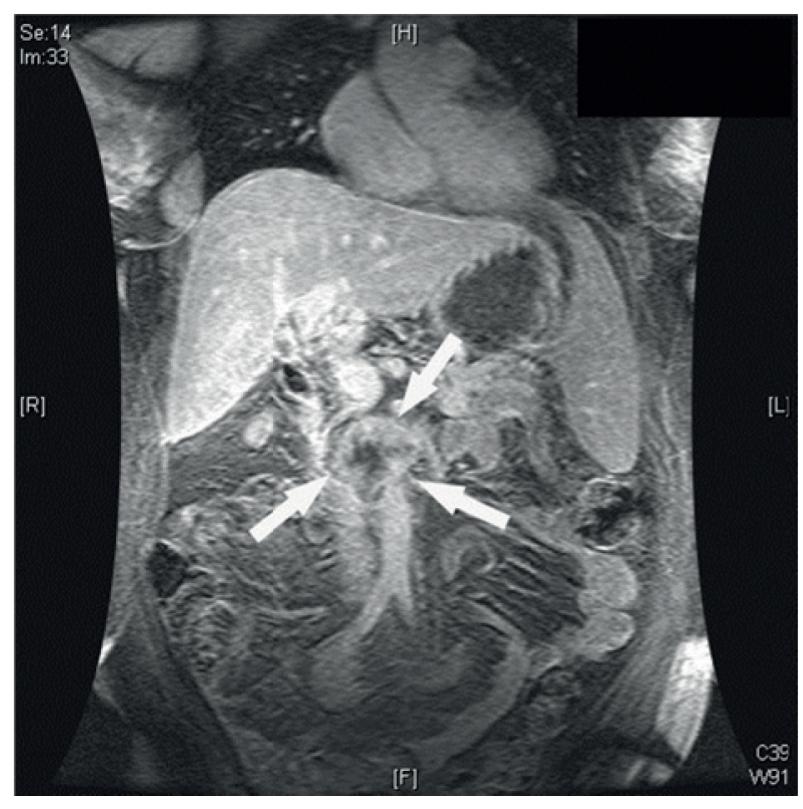

Figure 3. Magnetic Resonance Imaging (MRI) After Liver Transplantation Showing Enlarged Hilar and Paraaortic Lymph Nodes, Which Were Proven to be a Metastatic Cholangiocarcinoma explant after LT, tacrolimus was replaced with sirolimus. Three months after LT, we observed a threefold increase in the level of liver enzymes and a viral load of about 9 $\times 10^{6} \mathrm{IU} / \mathrm{mL}$. The findings of a liver biopsy revealed the recurrence of hepatitis $C$ virus (HCV) infection. The patient was administered $180 \mu \mathrm{g}$ of peginterferon alpha-2a (weekly) and $800 \mathrm{mg}$ of ribavirin (daily). Three months later, the level of liver enzymes increased rapidly and the measured viral load was undetectable. A repeat liver biopsy suggested moderately acute cellular rejection. The patient was treated with a 3-day course of pulse steroids, which resulted in a significant decline in the level of liver enzymes. Ultrasonography revealed a mass in the porta hepatis. Serum CA19-9 level was markedly elevated (255 $\mathrm{U} / \mathrm{mL}$ ), and the patient began experiencing vague abdominal pain. MRI confirmed the findings of enlarged hilar and paraaortic lymph nodes that were suggestive of metastases (Figure 3); ultrasound (US)-guided biopsy confirmed cholangiocarcinoma recurrence. Unfortunately, the patient's functional status deteriorated progressively, and serial chest plain radiographs showed an increase in the extent and number of lung metastases. The patient died from sepsis and respiratory failure 9 months after LT (Table 1).

\section{Discussion}

Combined HCC and cholangiocarcinoma is a rare form of primary liver cancer that usually presents as "mixed tumors", wherein regions of hepatocellular and biliary epithelial differentiation are intimately mixed within the same tumor (7-10). However, in extremely rare cases, combined HCC and cholangiocarcinoma may present as "collision tumors", wherein the discrete foci of HCC and cholangiocarcinoma arise separately within the liver with no direct contact between the 2 tumors (11-15). Our patient had not been exposed to environmental carcinogens; however, genetic predisposition to developing tumors was not tested. Previous reports have shown poor survival rates and high tumor recurrence rates after LT in patients with cholangiocarcinoma (16). Although LT for cholangiocarcinoma remains controversial, most LT centers do not consider patients with cholangiocarcinoma as suitable candidates for LT (17-20). Cholangiocarcinoma in cirrhotic livers is difficult to diagnose and can be easily mistaken for HCC. Cholangiocarcinoma should always be considered if patients show elevated serum CA19-9 levels and an atypical vascular pattern on dynamic imaging (1, 21); moreover, targeted biopsy or fine-needle aspiration should always be performed in such patients for ruling out cholangiocarcinoma before LT is considered (22). Our patient received a liver from a 27-year-old deceased male donor who was in good health; our patient had an uneventful surgical and postoperative course. Because of positive findings of cytomegalovirus serology in the donor and recipient, the recipient was administered gan- 
ciclovir for prophylaxis. Despite the recurrence of HCV infection, followed by an episode of acute cellular rejection, the patient responded well to standard treatment. We believe that the increase in the extent and number of intra-abdominal and pulmonary metastases might have led to sepsis, respiratory failure, and death.

\section{Conclusions}

Collision tumor resulting from combined HCC and cholangiocarcinoma in a cirrhotic liver is rare and has a negative impact on the outcome of LT. Atypical vascular pattern and elevated serum CA19-9 levels are suggestive of such tumors; patients with these findings should undergo a targeted biopsy to rule out the coincidental occurrence of cholangiocarcinoma LT is considered.

\section{Acknowledgments}

None declared.

\section{Authors' Contribution}

None declared.

\section{Financial Disclosure}

None declared.

\section{Funding/Support}

None declared.

\section{References}

1. Bruix J, Sherman M. Management of hepatocellular carcinoma. Hepatology. 2005;42(5):1208-36.

2. Chen LD, Xu HX, Xie XY, Xie XH, Xu ZF, Liu GJ, et al. Intrahepatic cholangiocarcinoma and hepatocellular carcinoma: differential diagnosis with contrast-enhanced ultrasound. Eur Radiol. 2010;20(3):743-53.

3. Leoni S, Piscaglia F, Golfieri R, Camaggi V, Vidili G, Pini P, et al. The impact of vascular and nonvascular findings on the noninvasive diagnosis of small hepatocellular carcinoma based on the EASL and AASLD criteria. Am J Gastroenterol. 2010;105(3):599-609.

4. Sherman M. The radiological diagnosis of hepatocellular carcinoma. Am J Gastroenterol. 2010;105(3):610-2.

5. Silva MA, Hegab B, Hyde C, Guo B, Buckels JA, Mirza DF. Needle track seeding following biopsy of liver lesions in the diagnosis of hepatocellular cancer: a systematic review and meta-analysis. Gut. 2008;57(11):1592-6.

6. Mazzaferro V, Regalia E, Doci R, Andreola S, Pulvirenti A, Bozzetti $\mathrm{F}$, et al. Liver transplantation for the treatment of small hepa- tocellular carcinomas in patients with cirrhosis. $N$ Engl J Med. 1996;334(11):693-9.

7. Hong CK, Yang JM, Kang BK, Kim JD, Kim YC, Chang UI, et al. A case of combined hepatocellular-cholangiocarcinoma with underlying schistosomiasis. Korean J Intern Med. 2007;22(4):283-6.

8. Pua U, Low SC, Tan YM, Lim KH. Combined hepatocellular and cholangiocarcinoma with sarcomatoid transformation: radiologic-pathologic correlation of a case. Hepatol Int. 2009;3(4):58792.

9. Willekens I, Hoorens A, Geers C, Op de Beeck B, Vandenbroucke F, de Mey J. Combined hepatocellular and cholangiocellular carcinoma presenting with radiological characteristics of focal nodular hyperplasia. World J Gastroenterol. 2009;15(31):3940-3.

10. Zhou YM, Yang JM, Wang B, Xu F, Tong Y, Li DQ. Combined hepatocellular carcinoma and cholangiocarcinoma: a case report and review of the literature. Hepatobiliary Pancreat Dis Int. 2007;6(6):656-9.

11. Goodman ZD, Ishak KG, Langloss JM, Sesterhenn IA, Rabin L. Combined hepatocellular-cholangiocarcinoma. A histologic and immunohistochemical study. Cancer. 1985;55(1):124-35.

12. Kwon Y, Lee SK, Kim JS, Ro JY, Yu E. Synchronous hepatocellular carcinoma and cholangiocarcinoma arising in two different dysplastic nodules. Mod Pathol. 2002;15(10):1096-101.

13. Nagafuchi Y, Okamoto K, Shono M, Higure A, Todoroki H, Itoh $\mathrm{H}$, et al. Separate histogenesis of combined hepatocellular and cholangiocellular carcinoma in two patients. Hepatogastroenterology. 1998;45(20):523-7.

14. Ng IO, Shek TW, Nicholls J, Ma LT. Combined hepatocellularcholangiocarcinoma: a clinicopathological study.J Gastroenterol Hepatol.1998;13(1):34-40.

15. Shigaki DM, Nekoba AC, Ide JY, Hardman JM, Tokeshi J. Synchronous liver cancers: A rare tumor combination in an elderly Japanese woman. Hawaii Med J. 2006;65(6):166-7, 78.

16. Ismail T, Angrisani L, Gunson BK, Hubscher SG, Buckels JA, Neuberger JM, et al. Primary hepatic malignancy: the role of liver transplantation. BrJ Surg. 1990;77(9):983-7.

17. Schwartz JJ, Hutson WR, Gayowski TJ, Sorensen JB. Liver transplantation for cholangiocarcinoma. Transplantation. 2009;88(3):2958

18. Shimoda M, Farmer DG, Colquhoun SD, Rosove M, Ghobrial RM Yersiz $\mathrm{H}$, et al. Liver transplantation for cholangiocellular carcinoma: analysis of a single-center experience and review of the literature. Liver Transpl. 2001;7(12):1023-33.

19. Sotiropoulos GC, Brokalaki EI, Molmenti EP, Beckebaum S, Frilling A, Malago M, et al. Liver transplantation for small solitary cholangiocellular carcinoma in cirrhosis: a medical mistake or a new indication? Transplantation. 2005;80(9):1356.

20. Weimann A, Varnholt H, Schlitt HJ, Lang H, Flemming P, Hustedt $\mathrm{C}$, et al. Retrospective analysis of prognostic factors after liver resection and transplantation for cholangiocellular carcinoma. $\mathrm{Br}$ J Surg. 2000;87(9):1182-7.

21. Rimola J, Forner A, Reig M, Vilana R, de Lope CR, Ayuso C, et al. Cholangiocarcinoma in cirrhosis: absence of contrast washout in delayed phases by magnetic resonance imaging avoids misdiagnosis of hepatocellular carcinoma. Hepatology.2009;50(3):7918 .

22. Gibbons D, de las Morenas A. Fine needle aspiration diagnosis of combined hepatocellular carcinoma and cholangiocarcinoma. A case report. Acta Cytol. 1997;41(4 Suppl):1269-72. 